ORIGINAL RESEARCH ARTICLE

\title{
Cytology and biochemical estimation of Neptunia prostrate (Lamk.) Baillon: an ethnomedicinal aquatic legume of Tripura, North East India. Anupam Guha $^{1 *}$, Debanjali Bhattacharjee ${ }^{1}$, Kanika Tripura ${ }^{1}$ and Abhijit Bhattacharya ${ }^{2}$ \\ ${ }^{1}$ Department of Botany, Women's College, Agaratala, Tripura, India. \\ ${ }^{2}$ Department of Chemistry, N. S. Mahavidyalaya, Udaipur, India.
}

Received: August 26, 2016; Accepted: September 9, 2016

\begin{abstract}
Neptunia prostrate (Lamk.) Baillon, commonly used as shoot vegetable in Tripura, North East India. Young shoots are used as vegetable in different forms of recipes of tribal and rural communities of this region. The utility of the vegetable as good source of protein and total amino acids with low level of phenolics and sugar clearly indicated its significance as useful health diet and alternative food supplement to the common people. The somatic chromosome number and karyomorphological details were also investigated in this plant. Somatic chromosome number was found to be $2 \mathrm{n}=56$ with karyotype formula $\mathrm{A}_{2} \mathrm{~B}_{42} \mathrm{C}_{12}$. The chromosome count and constancy of the karyotype with biochemical analysis recorded in the present study.
\end{abstract}

Key words: Neptunia prostrata; Somatic chromosome; Biochemical estimation

\section{Introduction}

Tripura is one of the smallest State of North Eastern parts of India and inhabited by the Tribal of Tibeto-Burman stock with as many as 19 different tribal communities and also represented by other communities like Bengali, Manipuri and Nepali since king dynasty in the State (Kirtikar et al., 1980). This ethological diversity has not only reflected their sociological and cultural aspects but also exposed unique traditional food habit and rural-herbal therapy (Chopra et al., 1986). The state is also rich in floristic diversity. Many of these ethno-botanical species and their traditional knowledge of uses associated with health care system are to be explored scientifically.

Neptunia prostrata (Lamk.) Baillon (Synonym: Neptunia oleracea. Family: Mimosaceae) is a miniature aquatic herb that floats by its white spongy structure. It has soft swollen stem with slender fibrous roots in flower bearing nodes. As a medicinal plant it is well-known to the herbal doctors of Tripura and other states of NorthEastern region. The tribal people of Tripura cultivate this plant both as vegetables as well as medicinal plant. They prepare various tasty dishes with this vegetable. Aqueous extract of this plant is used in the treatment of jaundice, sores of tongue, diarrhoea with bleeding, epileptic convulsions, earache etc. The paste of this plant is applied in leucorrhoea (Bhoomannaver et al., 2004). The plant is considered as refrigerant and astringent (Nandakarni, 2005). It is used to treat fever by applying the infusion of the whole plant on the body of the patient. Juice of the stem is dropped into ear to relieve earache. Roots are employed in late stage of syphilis. The powder root is applied over the nose to treat Syphilitic ulcer of the nose while decoction is taken to treat Syphilis (Ong, 2008). Considering its versatile activities, an effort has been made to study karyomorphological nature of the species at cytological level along with the biochemical activity of the plant.

\section{Materials and Methods}

The shoot tips of Neptunia prostrate was collected from the wet lands of Mandwi, West Tripura were grown in the water tanks of experimental garden of Women's College, Agartala. Plant was accordingly described and recorded. The plant was identified consulting authentic floristic literatures like Flora of Tripura (Deb, 1981), Flora of Assam (Kangilal, 1939) and Flora of British-India (Hooker, 1882). Cross examination of the specie was done consulting with Dr. Nalini Kanta Chakraborty, ExReader, Department of Botany, M. B. B. College, Agartala. Finally, voucher specimen was prepared following conventional methods (Jain, 1989) deposited in the Departmental Herbarium.

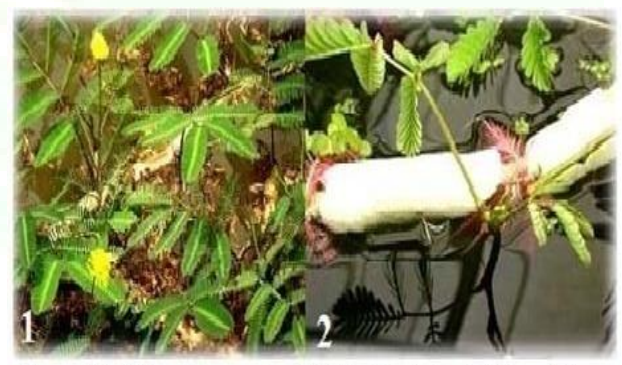

Figures: 1) Fresh Neptunia prostoata (Lamk) Baillon (Whole plant), 2) Spongy-Fibrous indumenta between the Stem Nodes of Neptunia prostrate (Lamk)Baillon.

\section{Somatic Chromosome Study:}

Shoot tips of Neptunia prostrate were collected from healthy plants (Fig. 1) for cytological studies. Outer covering of young leaves of shoot tip were removed and extreme tips measuring $0.5-1.0 \mathrm{~mm}$ were pretreated with saturated pDB (par- dichlorobenzene) solution in freezing temperature $\left(4^{\circ} \mathrm{C}\right)$ for 5 minutes

\footnotetext{
${ }^{*}$ Corresponding Author:

Dr. Anupam Guha,

Assistant Professor,

Department of Botany, Women's College,

Agartala-799001, Tripura, India.

E-mail: guha anupam@yahoo.com
}

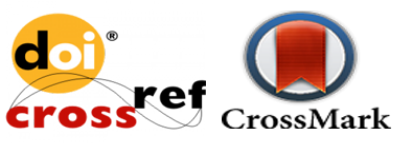


and finally in $12^{\circ} \mathrm{C}$ for 5.30 hours. The shoot tips were fixed in solution of acetic acid and ethyl alcohol mixture (1:3) at room temperature for overnight. After that they were treated with $45 \%$ acetic acid for 15 minutes and stained in a solution of $2 \%$ aceto-orcein and $1(\mathrm{~N}) \mathrm{HCl}(9: 1)$ mixture with warming for 3-4 seconds. Staining was carried out for overnight.

After staining the shoot tips were squashed in $45 \%$ acetic acid and studied under compound microscope. At least 10 observations were made from such treatments. Chromosomes of the plates were drawn using oil immersion objective (x 1460). Measurement of chromosomal complements like absolute length of the chromosome, length of short arm and long arm and $\mathrm{F} \%$ are carried out for each complement with 10 different metaphase plates. Detailed karyotype table was constructed from the well spread metaphase plates using total length, short arm, long arm and $\mathrm{F} \%$ of the chromosome complements and types of the chromosome complements. The $\mathrm{F} \%$ was determined by using the following formula:

$$
\begin{aligned}
& \text { Short arm length } \\
& \text { F \% }=\text { - Total length of chromosome }
\end{aligned}
$$

Total Forma percentage (TF \%) of chromosomal complements (Levan, 1964) was also calculated.

\section{Biochemical study:}

Fresh leafy young shoots of Neptunia prostrate was used for biochemical analysis. The fresh twigs were washed with double distilled water repeatedly and white spongy portion of the stem (Fig. 2) was removed. The exposed soft stem and leafy twigs were used for analysis. Nutritional value as biochemical characters like protein, phenol, sugar and total free amino acids were estimated following the standard methods of Lowry et al., (1951), Swain and Hills (1959), Hodge Hofreiter (1962) and Sadasivam and Manickam (1992) respectively.

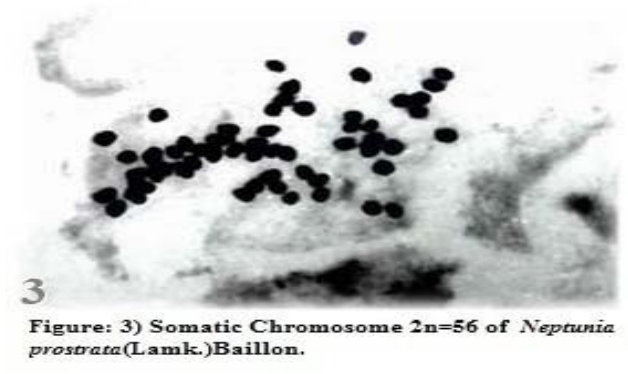

\section{Result and Discussions}

The somatic chromosome number of the Neptunia prostrate is determined and found to be $2 \mathrm{n}=56$ (Fig.3). This finding is also collaborated with previous observation (Turner, 1960). Characteristics measurements of chromosomal complements are performed from the 10 different chromosomal measurements, average value of each complement was determined, and presented in Table 1. Absolute size of the chromosomes ranged from $1.35 \mu \mathrm{m}$ to $5.00 \mu \mathrm{m}$ with a pair of chromosomes having secondary constriction (Table 1). The secondary constriction is associated with the short arm of the chromosomal complement having an absolute length of $4.17 \mu \mathrm{m}$. The total length of haploid chromosomal complement is $92.94 \mu \mathrm{m}$ and the total forma percentage (TF \%) is 33.90. On the basis of primary constriction and size of chromosomal complements, the chromosomes are classified into three morphological types:

Type A: Chromosomes with an average size of $4.17 \mu \mathrm{m}$ having nearly median ( $\mathrm{nm}$ ) primary constriction and sub-terminal (st) secondary constriction.

Type B: Chromosomes with an average size range of $5.00 \mu \mathrm{m}$ to $2.50 \mu \mathrm{m}$ having nearly sub median (nsm) and sub median(sm) primary constriction.

Type C: Chromosomes with size range of $1.90 \mu \mathrm{m}$ to $1.35 \mu \mathrm{m}$ and bears nearly sub median (nsm) primary constriction.

Based on chromosomal typification, the karyotype formula of Neptunia prostrate is found to be $\mathrm{A}_{2} \mathrm{~B}_{42} \mathrm{C}_{12}$. The somatic chromosome of Neptunia prostrates show homogenecity with slight size variation. The $\mathrm{TF} \%$ value indicates symmetry of chromosomes to a certain extent. Relatively less size differences between the chromosomes of the complement suggests its karyotype is to be considered as slightly asymmetric one and according to degree of asymmetry, the karyotype of the species (Table 2) belongs to the category $3 \mathrm{~A}$ (Stebbins,1971). The chromosome count and constancy of the karyotype recorded in the present taxon could be utilised to measure the cytological as well as karyomorphological variability among the ecotypic population of the species.

Biochemical characters of the apical young leafy twig, shoot, and leaf were analysed and revealed high protein and total free amino acid with low level of phenolic and sugar content (Table 3).

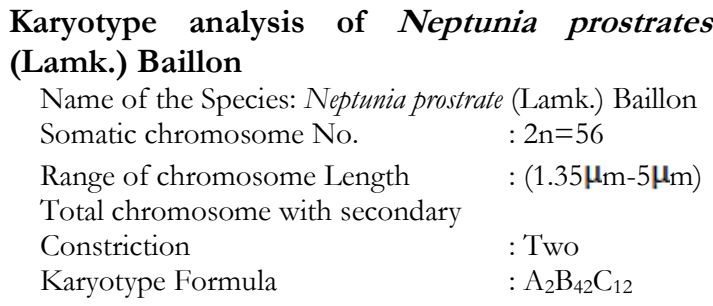

Karyotype analysis of Neptunia prostrates Name of the Species: Neptunia prostrate (Lamk.) Baillon Somatic chromosome No. $\quad: 2 \mathrm{n}=56$ Total chromosome with secondary Karyotype Formula 
Table 1: Karyomorphological characteristics of the Neptunia prostrate (Lamk.) Baillon

\begin{tabular}{|c|c|c|c|c|c|c|}
\hline $\begin{array}{c}\text { Type of } \\
\text { Chromosome }\end{array}$ & $\begin{array}{c}\text { No. of } \\
\text { Chromosome }\end{array}$ & $\begin{array}{l}\text { Length of } \\
\text { whole arm } \\
(\mu \mathrm{m} \pm \mathrm{SD})\end{array}$ & $\begin{array}{l}\text { Length of } \\
\text { short arm } \\
(\mu \mathrm{m} \pm \mathrm{SD})\end{array}$ & $\mathrm{F} \%$ & $\begin{array}{c}\text { Nature of } \\
\text { primary } \\
\text { constriction }\end{array}$ & Remarks \\
\hline A & 2 & $4.17 \pm 0.37$ & $\begin{array}{l}0.42 \pm 0.41 \\
0.83 \pm 0.00\end{array}$ & $\begin{array}{l}10.07 \pm 0.37 \\
19.90 \pm 0.37\end{array}$ & -- & $\begin{array}{l}\text { Presence of two } \\
\text { constrictions. } \\
\text { One is sub-terminal } \\
\text { and the other is sub- } \\
\text { median in position }\end{array}$ \\
\hline \multirow{10}{*}{ B } & 4 & $5.00 \pm 0.12$ & $1.25 \pm 0.39$ & $25.00 \pm 0.32$ & $\mathrm{nsm}$ & \\
\hline & 4 & $4.58 \pm 0.18$ & $1.67 \pm 0.52$ & $36.46 \pm 0.35$ & $\mathrm{nsm}$ & \\
\hline & 4 & $4.58 \pm 0.24$ & $1.25 \pm 042$ & $27.29 \pm 0.37$ & $\mathrm{nsm}$ & \\
\hline & 8 & $4.17 \pm 0.36$ & $1.25 \pm 0.39$ & $29.98 \pm 0.54$ & $\mathrm{nsm}$ & \\
\hline & 2 & $3.75 \pm 0.43$ & $0.83 \pm 0.35$ & $22.13 \pm 0.22$ & $\mathrm{sm}$ & \\
\hline & 4 & $3.75 \pm 0.26$ & $1.25 \pm 0.44$ & $33.33 \pm 0.26$ & $\mathrm{nsm}$ & \\
\hline & 2 & $3.33 \pm 0.34$ & $0.83 \pm 0.32$ & $24.92 \pm 0.54$ & $\mathrm{sm}$ & \\
\hline & 4 & $3.33 \pm 0.41$ & $1.25 \pm 0.43$ & $37.54 \pm 0.46$ & $\mathrm{nsm}$ & \\
\hline & 4 & $2.92 \pm 0.21$ & $1.25 \pm 0.51$ & $42.81 \pm 0.45$ & $\mathrm{nsm}$ & \\
\hline & 6 & $2.50 \pm 0.23$ & $0.83 \pm 0.47$ & $33.20 \pm 0.47$ & $\mathrm{nsm}$ & \\
\hline \multirow{3}{*}{$\mathrm{C}$} & 4 & $1.90 \pm 0.34$ & $0.82 \pm 0.42$ & $43.15 \pm 0.57$ & $\mathrm{nsm}$ & \\
\hline & 6 & $1.35 \pm 0.27$ & $0.65 \pm 0.41$ & $48.14 \pm 0.63$ & $\mathrm{nsm}$ & \\
\hline & 2 & $1.35 \pm 0.41$ & $0.55 \pm 0.53$ & $40.74 \pm 0.42$ & $\mathrm{nsm}$ & \\
\hline
\end{tabular}

Table 2: Stebbins catagorization of karyotype Neptunia prostrate (Lamk.) Baillon

\begin{tabular}{ccccc}
\hline Ratio & \multicolumn{4}{c}{ Proportion of the chromosome with arm ratio <2:1 } \\
\hline \multirow{2}{*}{$\begin{array}{c}\text { Largest/Smallest } \\
<2: 1\end{array}$} & 0.00 & $0.01-0.50$ & $0.51-0.90$ & 1.00 \\
& & & $3 \mathrm{~A}$ & Neptunia prostrate \\
& & & $3 \mathrm{~A}$ & $4 \mathrm{~A}$ \\
\hline
\end{tabular}

Table 3: Biochemical estimation of Leafy stem of Neptunia prostrate (Lamk.) Baillon

\begin{tabular}{lllll}
\hline Sample used & \multicolumn{4}{c}{ Biochemical parameters (mg. /g. Fr.wt.) } \\
\hline Apical young & Protein & Phenol & Sugar & Total free amino acids \\
leafy Twig & $21.34 \pm 0.24$ & $1.16 \pm 0.14$ & $1.43 \pm 0.53$ & $105.45 \pm 0.71$ \\
Shoot & $16.32 \pm 0.37$ & $1.25 \pm 0.25$ & $1.97 \pm 0.33$ & $96.22 \pm 0.36$ \\
Leaf & $12.33 \pm 0.54$ & $0.76 \pm 0.21$ & $2.22 \pm 0.37$ & $185.12 \pm 0.43$ \\
\hline
\end{tabular}

\section{Conclusion}

Karyomorphological account of the taxon with a karyotype formula $\mathrm{A}_{2} \mathrm{~B}_{42} \mathrm{C}_{12}$ are described for the first time from Tripura in the present communication. The karyotype revels high homogencity. The preliminary information on biochemical analysis showed that the leafy vegetable may be used as health diet and alternative food supplement.

\section{Acknowledgement}

The authors are grateful to Dr. Nalini Kanta Chakraborty, Ex-Reader, Department of Botany, M. B. B. College, Agartala for identification and authentication of the plant materials and valuable suggestions during the work.

\section{References}

1. Kirtikar KR and BD Basu. "Indian Medicinal Plants."1(1980) 904 Print

2. Chopra RN, SL Nair and IC Chopra "Supplement to Glossary of Indian Medicinal Plants." CSIR, New Delhi (1986)73 Print

3. Bhoomannavar VS, BC Hatapakki, HV Kumar, RS Setty and HM Sures "Laxative Activity of Pods of Neptunia prostrata in mice." Indian J Nat Prod 20.1(2004) 43-45. Print

4. Nandakarni KM. "Indias Materia Medica, Reprin." Proplar Prakashan Pvt. Ltd., Mumbai, 1. (2005) 847.Print

5. Ong HC. "Vegetables for Health and Healing." Utusam Publication. Kuallampur, (2008) 187.Print

6. Deb DB. "The Flora of Tripura." Today and tomorrow's Publ., New Delhi, (1981). Print

7. Kangilal PC. and RN Dev. "Flora of Assam. Omsons Publ.” New Delhi, (1939). Print

8. Hooker JD. "The Flora of British India." SIC, L. Reeve \& Co., London. (1882). Print

9. Jain SK. "Methods and approaches of Ethnobotany." Society of Ethnobotanist, CDRI, New Delhi (1989). Print

10. Levan A, K Fredgra and AA Sandbery. "Nomenclature for centromeric position on chromosomes." Hereditas, 52 (1964).201-220. 
onlinelibrary.wiley.com/doi/10.1111/j.16015223.

11. Lowry OH, ND Rosebrough, AL Farr and RJ Randall. "Protein measurement with folin phenol reagent" J Biol Chem, 193(1951). 265-275. InfoSource/ISPDFs/Lowry\%201951.pdf

12. Swain J and WE Hills. "The phenolic constituents of Prunus domestica I." J Sci. Food Agric 10(1959). 63-68. Print

13. Hodge JE and BT Hofreiter "Method in carbohydrate chemistry." Academic Press London, 1. (1962) 380-394.Print.

14. Sadasivam OS and A Manickam. "Biochemical methods." New Age Inter Pub. Ltd. 2(1992) New Delhi.Print
15. Turner BL and OS Fearing. "The basic chromosome number of the genus Neptunia (Leguminosae-Mimosoideae).” Madrono,15 (1960).184-187. Print

16. Stebbins GL, Chromosomal evolution in higher plant, (1971), Edward Arnold., London. Print

\section{Cite this article as:}

Anupam Guha, Debanjali Bhattacharjee, Kanika Tripura and Abhijit Bhattacharya. Cytology and biochemical estimation of Neptunia prostrate (Lamk.) Baillon: an ethnomedicinal aquatic legume of Tripura, North East India. Annals of Plant Sciences 5.9 (2016): 1424-1427.

DOI: http://dx.doi.org/10.21746/aps.2016.09.003

Source of support: Nil.

Conflict of interest: None Declared 